\title{
A percepção e a produção das fricativas alveolares da língua portuguesa por hispano-falantes
}

Perception and production of portuguese alveolar fricatives by spanish speakers

\author{
Rosane Silveira \\ Universidade Federal de Santa Catarina \\ Tharen Teixeira de Souza \\ Universidad del Norte - Colômbia
}

Resumo

Neste estudo, verificamos a correlação entre a percepção e a produção dos sons /s/ e /z/ por hispano-falantes aprendendo português e de que modo o nível de proficiência, a ortografia e o contexto fonológico afetam essa correlação. Os dados foram coletados com 15 participantes adultos de níveis de proficiência diversos. Foram aplicados um teste de percepção e um de produção, os quais incluíram o mesmo conjunto de 40 palavras (que constituíam 20 pares mínimos) contrastando os sons /s/ e /z/ (ex.: casa / caça; fase / face). Para o teste de percepção, os participantes ouviam uma palavra e assinalavam se ela continha o som /s/ ou $|z|$. Para o teste de produção, os participantes gravaram a leitura oral de cada palavra. Os dados mostram correlaçōes fracas entre percepção e produção e uma maior dificuldade na produção de $|z|$, mas também indicam que a ortografia e o contexto fonológico afetam a produção das fricativas alveolares.

\section{Palavras-Chave}

Percepção, Produção, Fricativas alveolares, Hispano-falantes. 


\section{Abstract}

This study examines the correlation between perception and production of the sounds /s/ and /z/ by Hispanic speakers learning Portuguese and how proficiency level, spelling and phonological context affect this correlation. Data were collected from 15 adult participants of various levels of proficiency. We administered a test of perception and production, which included the same set of 40 words (which were 20 minimal pairs) contrasting the sounds /s/ and /z/ (e.g.: casa / caça; fase / face). For the perception test, participants listened to a word and marked if it contained /s/ or $\mid \mathrm{z} /$. For the production test, participants recorded the oral reading of each word. The data show weak correlations between perception and production and greater difficulty in the production of $/ z /$, but also indicate that spelling and phonological context affect the production of alveolar fricatives.

\section{Keywords}

Perception, Production, Alveolar fricatives, Spanish speakers. 


\section{Introdução}

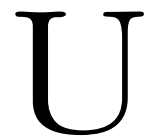

$\mathrm{m}$ tópico frequentemente discutido e bastante controverso no campo da interfonologia, isto é, em estudos que investigam a aquisiçãa fonológica de uma segunda língua (L2), é a relação entre a percepção e a produção dos sons da L2 (ROCHET, 1995; FLEGE; MACKAY; MEADOR, 1999; YOUNG-SCHOLTEN, 2002). No centro do debate está a questão do quanto a produção dos sons da L2 é precedida pela percepção dos mesmos, ou se a percepção é apenas uma dos elementos que contribuem para a produção dos sons da L2. Dentre esses outros elementos estão a utilização de informações visuais, obtidas quando o aprendiz de L2 observa os movimentos articulatórios de um falante da língua-alvo (HAZAN; SENNEMA; FAULKNER et al., 2006; KLUGE, 2010), bem como o uso de informações sobre as correpondências grafofono-fonológicas na L2 (BASSETTI, 2009; ZIMMER; SILVEIRA; ALVES, 2009).

O presente estudo pretende contribuir com esse debate sobre a relação entre a percepção e a produção, reportando dados de um estudo com hispanofalantes que são aprendizes de português. Mais especificamente, o estudo teve como objetivo verificar a correlação entre a percepção e a produção das fricativas alveolares /s/ e /z/ em posição de ataque silábico ('doce' [s], 'doze' [z]) por esses aprendizes e de que modo a ortografia, o contexto fonológico e o nível de proficiência dos participantes afetam essa relação.

\section{A aquisição de /s/ e /z/ por hispano-falantes}

Akerberg (2004) relata resultados de estudos em que entrevistou alunos hispano-falantes, indagando sobre as vantagens e desvantagens de estudar uma língua próxima como o português. Os alunos destacaram dificuldades com a pronúncia, entre as quais consta a dificuldade em ouvir e produzir o contraste entre a sibilante surda $/ \mathrm{s} / \mathrm{e}$ a sonora $/ \mathrm{z} /$. Tal dificuldade é facilmente constatada 
quando interagimos com falantes nativos de espanhol expressando-se em língua portuguesa. Isso porque uma importante diferença entre o inventário fonêmico do português brasileiro (PB) e do espanhol diz respeito ao status dos sons /s/ e /z/ (CONDE, 2001; CRISTÓFARO-SILVA, 2002). Em PB, as duas fricativas alveolares existem como fonemas, o que pode ser atestado com a ocorrência de inúmeros pares mínimos, tais como 'casa' ['kazə] e 'caça' ['kasə]; 'doze' ['dozi] e 'doce' ['dosi]. Já em espanhol, o inventário fonêmico traz apenas a fricativa alveolar surda /s/. Cabe ressaltar que, em posição de coda silábica, em PB, o fonema /s/ tem como alofones [s], [S], [z] e [3] ('dois' [doIs] ou [doI $\left.\int\right]$, 'mesmo' ['mezmu] ou ['mezmu] (CRISTÓFARO-SILVA, 2002). A ocorrência desses alofones depende do contexto fonológico que sucede /s/ e de variação dialetal. Como o presente estudo investiga a percepção de /s/ e /z/ em posição de ataque silábico apenas, na qual ocorrem apenas /s/ e /z/, não entraremos em detalhes sobre os possíveis alofones das fricativas alveolares em PB. No entanto, é importante destacar que, no presente estudo, as duas fricativas alveolares foram testadas nos seguintes contextos fonológicos e com as seguintes grafias:

- entre dois sons vocálicos, com as grafias $\langle\mathrm{s}\rangle,\langle\mathrm{z}\rangle,\langle\mathrm{ç}\rangle,\langle\mathrm{ss}\rangle \mathrm{e}$ $<\mathrm{c}>$ : $\left(\mathrm{V}_{-} \mathrm{V}\right.$, 'casa' $[\mathrm{z}]$, 'doze' $[\mathrm{z}]$, 'doce' [s], 'posse' [s], 'caça' $\left.[\mathrm{s}]\right)$

- em início de palavra e seguido por uma vogal, com as grafias $<s>$, $<\mathrm{z}>$ e $\left\langle\mathrm{c}>\right.$ : $^{1}$ (\#_V, 'zelo' [z], 'cem' [s], 'selo' [s]).

Akerberg (2001) constatou que, nos dois testes de percepção aplicados, cada um com dois grupos de hispano-falantes, havia uma tendência a ouvir o som /s/, mesmo em palavras que continham, na verdade, o som /z/. Embora os participantes não tivessem acesso às palavras escritas que integravam o teste de percepção desse estudo, a autora relata que a ortografia influenciou consideravelmente os resultados do teste de percepção, pois os participantes pareciam "se apoiar numa imagem visual da palavra escrita” (p. 116). Tal observação também é corroborada por outros autores que investigam a aquisição dos sons da língua inglesa (YOUNG-SCHOLTEN; ARCHIBALD, 2000; SILVEIRA, 2007; BASSETTI, 2009).

Resultados semelhantes foram obtidos no estudo de Akerberg (2001) para a grafia <ç>, percebida como /z/ em palavras cognatas do espanhol ('coração' / corazón), ou mesmo em outras palavras que não eram cognatas (ex.: 'debruçar' / acodar). A autora argumenta que os alunos tendem a atribuir o som /z/ à grafia 
$<$ <̧>, devido ao fato de essa grafia ser típica do português e de que algumas palavras cognatas do espanhol são grafadas com $<\mathrm{z}>$ (ex. corazón, danza). A grafia $<s>$ apresentou resultados diversos, dependendo do status da palavra na língua espanhola. Para palavras cognatas, porém com grafia diferente em espanhol (ex: 'sapato' / zapato), a tendência entre os alunos menos proficientes era de serem influenciados pela grafia do espanhol, o que significa que ouviam o som $/ z /$ na palavra 'sapato'. Para palavras cognatas com a mesma grafia nas duas línguas (ex. 'música', 'generoso'), a tendência era o processamento rápido da palavra, sem que se prestasse "atenção aos detalhes fonéticos" (p. 117), resultando na percepção da grafia $<s>$ em contexto intervocálico como /s/, como acontece no espanhol. Já para palavras inexistentes no espanhol (ex.: 'cheiroso', os alunos pareciam se concentrar mais nos detalhes fonéticos e percebiam corretamente a presença do som $/ z /$. No que concerne a grafia $<z>$, a tendência era que os alunos percebessem corretamente a presença do som $/ \mathrm{z} /$, especialmente quando a palavra continha a letra $<\mathrm{z}>$ no início da palavra (ex.: 'zona').

Embora Akerberg (2001) apresente os resultados por palavras de maneira bastante abreviada, na forma de apêndice, decidimos tabular os resultados obtidos pela autora utilizando as informaçóes por ela apresentadas, de forma a obter as porcentagens totais de acertos nos testes de percepção. Como explicado acima, a autora utilizou dois testes de percepção. $O$ primeiro deles continha 50 palavras com $/ \mathrm{s} / \mathrm{e} / \mathrm{z}$, em grafias diversas, e foi aplicado com um grupo de $23 \mathrm{e}$ outro de 16 participantes. O segundo teste continha 20 palavras e foi completado por um grupo de 17 e outro de 14 participantes. Ao tabular os resultados, observamos que o índice total de acertos para o teste 1 foi de $60,35 \%$ para o grupo 1 e $58,75 \%$ para o grupo 2. Já o segundo teste revelou um total de $46,47 \%$ de acertos para o grupo 3 e $60,71 \%$ para o grupo 4 . Os resultados por tipo de som também foram tabulados e são apresentados na TAB. 1. Em geral, observamos que o $/ \mathrm{z} /$ foi melhor percebido no teste 1 , mas o $/ \mathrm{s} /$ foi mais bem percebido no teste 2 . Talvez esses resultados estejam relacionados ao tipo de palavras incluídas nos testes, visto que, para o som $/ \mathrm{s} /$, o teste 2 traz apenas palavras grafadas com $<c ̧>\mathrm{e}<\mathrm{ss}>$, enquanto o teste 1 apresenta várias grafias. Além disso, o teste 2 incorpora palavras de baixa frequência de uso em PB. 
TABELA 1

Porcentagem de acertos nos dados dos testes de Percepção de Akerberg (2001)

\begin{tabular}{c|c|c|c|c|c}
\hline & \multicolumn{2}{c|}{ Teste 1 } & \multicolumn{2}{c}{ Teste 2 } \\
\hline & $/ \mathrm{s} /$ & $\mid \mathrm{z} /$ & & \multicolumn{1}{c}{$/ \mathrm{z} /$} & \multicolumn{1}{c}{$\mid$} \\
\hline Grupo 1 & 47,83 & 55,83 & Grupo 3 & 47,6 & 41,76 \\
Grupo 2 & 48,25 & 52,75 & Grupo 4 & 51,43 & 45,71 \\
\hline
\end{tabular}

Com relação à produção das duas fricativas alveolares, Sobral, Nobre e Freitas (2006) conduziram um estudo analisando o desempenho de aprendizes falantes de espanhol e italiano na leitura de 16 sentenças contendo vários sons do PB. Falando especificamente das duas fricativas alveolares, elas foram testadas em vários contextos silábicos e fonológicos (e.g., ataque silábico, coda, entre vogais, seguidas de consoantes surdas e sonoras, seguidas de pausa). Os resultados para os três aprendizes hispano-falantes mostram que o desempenho deles na produção de /s/ foi excelente (100\% de acertos), mas que esses aprendizes apresentaram bastantes dificuldades na produção de /z/ (23,1\% de acertos).

Os resultados dos estudos relatados acima ratificam que a percepção e a produção de /s/ e /z/ impõem dificuldades aos aprendizes hispano-falantes de PB. O conceito de classificação equivalente, proposto por Flege (1987) pode ser útil para compreender tais dificuldades. Segundo Flege, os aprendizes de uma L2 interpretam os sons da língua-alvo com base no inventário fonético de sua língua materna (L1). Visto que o sistema da L1 é a base para a aquisição dos sons da L2, os aprendizes produzem algo próximo dos sons da língua-alvo, mas raramente conseguirão realmente produzir os sons da L2. Ao propor o Modelo de Aprendizagem da Fala, Flege (1995) enfatiza que os aprendizes de L2 percebem os sons da L2 através de uma espécie de "filtro" da L1, o que torna difícil a atentar para certas características dos sons da L2 que são de algum modo diferentes de sons que os aprendizes interpretam como sendo similares a sons de sua L1.

Tendo como base os estudos anteriores sobre a aquisição de /s/ e /z/ e buscando enriquecer o debate sobre a relação entre percepção e produção, o presente estudo pautou-se nas seguintes perguntas de pesquisa:

1) Como é o desempenho dos participantes nos testes de percepção e produção dos sons $/ \mathrm{s} / \mathrm{e} / \mathrm{z}$ ? 
2) Qual o tipo de correlação entre a percepção e a produção dos sons /s/ e /z

3) Qual o tipo de correlação entre a percepção e a produção dos sons /s/ e /z/ e o nível de proficiência dos participantes?

4) Em que medida a percepção e a produção dos sons /s/ e /z/ são influenciadas pela ortografia e pelo contexto fonológico?

A próxima sessão apresenta detalhes sobre a metodologia de pesquisa adotada, fornecendo informações sobre os participantes, os instrumentos de pesquisa, bem como os procedimentos de coleta e análise dos dados.

\section{Metodologia}

Os dados da pesquisa foram coletados com 15 alunos do curso de Português como Língua Estrangeira (PLE) da Universidad del Norte, na Colômbia, sendo dez do sexo feminino e cinco, masculino, com idades entre 13 e 32 anos (média $=21,26)$. O ensino de português na Universidad del Norte é oferecido pelo Instituto de Idiomas da instituição, como um curso de extensão. $\mathrm{O}$ objetivo do programa é atender à demanda de estudantes da própria universidade, bem como da comunidade externa. Atualmente, o curso vai do Básico ao Intermediário e possui seis níveis, com 50 horas cada um - normalmente quatro horas semanais, dois dias na semana. Os cursos de PLE dessa instituição adotam o livro Novo Avenida Brasil, volumes 1, 2 e 3, além de outros materiais didáticos definidos pelo professor, em cada nível.

Os participantes do presente estudo apresentavam diferentes níveis de proficiência em PLE e estavam matriculados nos seguintes cursos: nível 1 (dez participantes), nível 3 (dois participantes), nível 4 (um participante) e nível 6 (dois participantes). Todos eram colombianos (11 da cidade de Barranquilla, os demais de outras cidades), sem experiência de aprendizagem de português em país de língua portuguesa.

Foram usados três instrumentos para coletar os dados: questionário, teste de produção e teste de percepção, aplicados nessa sequência. Primeiramente, os participantes responderam ao questionário que trazia o termo de consentimento para o uso dos dados e indagava sobre a idade, a cidade de residência e experiências com a aprendizagem de PLE. Em seguida, os participantes realizaram o teste de produção, que consistia na leitura oral e gravação, em arquivo de áudio, de 48 palavras apresentadas individualmente na tela de um computador. 
Cada participante recebeu uma versão do teste na qual a ordem de apresentação das palavras era diferente, de modo que possíveis efeitos de ordem de apresentação das palavras pudesse ser minimizado. Dessas 48 palavras, oito eram distratores distribuídos ao longo do teste; as 40 palavras restantes formavam 20 pares mínimos contendo os sons /s/ e /z/ em posição de ataque silábico e grafados de maneiras diversas. O QUADRO 2 lista as palavras que integraram o teste de produção.

\section{QUADRO 1}

Palavras incluídas nos testes de percepção e produção

\begin{tabular}{l|l|l|l|l|l}
\hline 1. & pesa & peça & 11. & presente & pressente \\
2. & casa & caça & 12. & zen & cem \\
3. & doze & doce & 13. & zelo & selo \\
4. & fase & face & 14. & zelar & selar \\
5. & lousa & louça & 15. & zoar & soar \\
6. & tose & tosse & 16. & zurrar & surrar \\
7. & pouso & posso & 17. & zinco & cinco \\
8. & azeite & aceite & 18. & cose & coce \\
9. & tese & tece & 19. & NASA & nasça \\
10. & viso & viço & 20. & rosa & roça \\
\hline
\end{tabular}

As mesmas palavras do teste de produção foram usadas no teste de percepção. No teste de percepção, porém, as palavras não foram apresentadas aos participantes em sua forma gráfica e foram distribuídas de maneira aleatória nos testes. Os participantes ouviam uma gravação em áudio contendo cada uma das palavras individualmente e clicavam na tela do computador para responder se a palavra continha o som /s/ ou /z/. Por exemplo, ao ouvir a palavra 'pesa', o participante assinalava na tela do computador qual dos dois fonemas a palavraalvo continha. Um exemplo do que aparecia na tela do computador para que o participante selecionasse o fonema que havia ouvido é apresentado a seguir.

\begin{tabular}{|l|l|l|}
\hline 1. & $\ldots \ldots \ldots / \mathrm{s} /$ & $\ldots \ldots \ldots . / \mathrm{z} /$ \\
\hline
\end{tabular}

Cada palavra só podia ser ouvida uma vez e o participante decidia quando avançar para ouvir a próxima palavra. Antes de iniciar o teste, uma das 
pesquisadoras fez uma sessão de treinamento com os participantes, utilizando palavras que não integravam o teste, visando familiarizar os participantes com os procedimentos.

A análise do teste de percepção consistiu na contagem das respostas corretas das 40 palavras contendo os sons /s/ e /z/. Já o teste de produção exigiu a transcrição fonética dos sons-alvo por parte das duas pesquisadoras, separadamente. Os poucos casos de discrepância nas transcriçõos para esse teste foram resolvidos em conjunto pelas duas pesquisadoras. Com base nas transcrições, o número de produçōes corretas foi calculado.

Os dados foram submetidos à análise estatística utilizando o programa SPSS (16.0). A análise dos histogramas e dos testes para verificar se os dados apresentavam distribuição normal (Shapiro-Wilktest) indicaram que duas variáveis apresentavam problemas sérios de curtose e assimetria, mostrando que os dados tinham de ser considerados não paramétricos. Por esse motivo, os testes estatísticos usados para comparar as médias dos testes de percepção e produção (pergunta de pesquisa 1) foram Friedman (ideal para comparar mais de três amostras não paramétricas emparelhadas) e Wilcoxon (ideal para comparar duas amostras não paramétricas emparelhadas). Para realizar as análises correlacionais (pergunta de pesquisa 2), o teste utilizado foi a correlação de Spearman, a melhor opção para dados não paramétricos. O nível de significância dos testes estatísticos foi estabelecido em $\alpha=.05$.

\section{Resultados e Discussão}

Com o objetivo de verificar a correlação entre a percepção e a produção das fricativas alveolares em posição de ataque silábico, a correlação entre percepção, produção e nível de proficiência, e de que modo a ortografia e o contexto fonológico afetam essa relação, quatro perguntas de pesquisa guiaram o presente estudo. A seguir, apresentamos e discutimos os resultados que nos permitem responder às perguntas de pesquisa.

1) Como é o desempenho dos participantes nos testes de percepção e produção dos sons /s/ e /z?

A TAB. 2 mostra os números totais de acertos, as médias aritméticas, as porcentagens e os números mínimo e máximo de respostas possíveis para os 
testes de percepção e produção. Os resultados podem ser visualizados de forma agrupada para o teste de percepção e para o teste de produção, bem como separadamente para cada uma das fricativas alveolares.

Como podemos observar na TAB. 2, em geral, o desempenho no teste de percepção (média de respostas corretas $=32,26$, o que equivale a $82,71 \%$ dos itens testados) foi melhor do que no teste de produção (média de respostas corretas $=22,40$, o que equivale a $57,43 \%$ dos itens testados). Quando o desempenho nos dois testes é analisado individualmente para cada um dos sons testados, vemos que o fonema / $\mathrm{z}$ / (média $=16,40(82 \%)$ ) foi percebido com um pouco mais de precisão do que /s/ (média = 14,93 (74,65\%)). Situação inversa é observada no teste de produção, no qual /s/ foi produzido corretamente com mais frequência $($ média $=15,80(83,15 \%))$ do que $/ z /($ média $=6,6(34,73 \%)$ ).

TABELA 2

Resultados para os testes de percepção e de produção

\begin{tabular}{l|r|r|r|r|r|r}
\hline & $\begin{array}{r}\text { Teste de } \\
\text { percepção }\end{array}$ & /s/ & /z/ & $\begin{array}{r}\text { Teste de } \\
\text { produção }\end{array}$ & \multicolumn{1}{c}{$/$ / } & |z/ \\
\hline Total & 470 & 224 & 246 & 336 & 237 & 99 \\
Média & 32,26 & 14,93 & 16,40 & 22,40 & 15,80 & 6,6 \\
Porcentagem & $(82,71 \%)$ & $(74,65 \%)$ & $(82,0 \%)$ & $(57.43 \%)$ & $(83,15 \%)$ & $(34,73 \%)$ \\
Mínimo-máximo & $26-38$ & $11-18$ & $12-19$ & $17-38$ & $6-19$ & $0-19$ \\
\hline
\end{tabular}

$\mathrm{N}=585$ (39 palavras * 15 participantes)

$\mathrm{N}$ para $/ \mathrm{z} /=300$ (20 palavras $* 15$ participantes $)$

$\mathrm{N}$ para $/ \mathrm{s} /=285\left(19^{2}\right.$ palavras $* 15$ participantes $)$

As médias agrupadas (i. e., incluindo os sons /s/ e /z/) dos testes de percepção $(32,26)$ e produção $(22,40)$ foram comparadas usando o teste de Wilcoxon, que revelou uma diferença significativa $(\mathrm{Z}=-3.29, \mathrm{p}=.001)$. Ou seja, os participantes apresentam melhor desempenho na percepção do que na produção dos sons /s/ e /z/.

Os dados também foram comparados levando em consideração cada um dos sons. Para isso, utilizamos o teste de Friedman, que permite comparar dados de três ou mais variáveis. No nosso caso, tínhamos dois sons e dois testes, o que resultou em quatro variáveis: percepção de /z/, produção de /z/, percepção de /s/ e produção de /s/. Ao comparar essas variáveis, o teste de Friedman indicou uma diferença significativa entre elas $\left(\mathrm{X}^{2}=19.01, \mathrm{p}<.001\right)$. Como o teste de 
Friedman não indica onde está a diferença entre as variáveis, rodamos testes de Wilcoxon para localizar as possíveis diferenças significativas.

Os testes de Wilcoxon revelaram o seguinte:

- $/ z /$ percepção e $/ z /$ produção: diferença significativa, $\operatorname{com} p=.001$. Ou seja, $/ z /$ é significativamente melhor percebido do que produzido.

- $/ \mathrm{s} /$ percepção e $/ \mathrm{s} /$ produção: diferença não significativa $(\mathrm{p}=.254)$. Ou seja, Is/ é percebido e produzido de maneira semelhante.

- /s/ percepção e / $/ \mathrm{z} /$ percepção: diferença não significativa $(\mathrm{p}=.058)$, embora $\mid z /$ tenha sido percebido corretamente com mais frequência e $o$ valor de $p$ seja muito próximo de .05 .

- /s/ produção e /z/ produção: diferença significativa, com $\mathrm{p}=008 . \mathrm{Ou}$ seja, $/ \mathrm{s} /$ é significativamente produzido corretamente com mais frequência do que $/ z /$.

Os resultados relacionados à percepção de $/ \mathrm{s} / \mathrm{e} / \mathrm{z} /$ diferem daqueles obtidos por Akerberg (2001), visto que nossos participantes obtiveram uma porcentagem de acertos bem mais elevada para os sons $/ \mathrm{s} / \mathrm{e} / \mathrm{z} /$. No entanto, assim como observou Akerberg no teste de percepção 1, houve, em nosso estudo, uma tendência para a melhor percepção de $/ z /$, o que não seria esperado, dado que esse som não existe na L1 dos participantes e na produção, tende a ser substituído por $/ \mathrm{s} /$. Os diferentes resultados entre os dois estudos podem estar relacionados com características das palavras testadas (cognatas, grafia, frequência de uso), bem como com os diferentes níveis de proficiência dos participantes. No que diz respeito à produção das duas fricativas alveolares, nossos resultados apontam para uma situação semelhante à constatada por Sobral, Nobre e Freitas (2006), visto que o desempenho dos participantes é muito melhor na produção $\mathrm{de} / \mathrm{s} /$ (embora não chegue a 100\% de acertos como no estudo de Sobral, Nobre e Freitas) do que de $/ z /$.

Tendo respondido à primeira pergunta de pesquisa, para a qual comparamos as médias dos testes de percepção e de produção para os dois sons testados, passaremos agora a apresentar os resultados para a segunda pergunta de pesquisa, que indaga sobre a correlação entre percepção e produção:

2) Qual o tipo de correlação entre a percepção e a produção dos sons /s/ e /z/

Correlaçôes de Spearman foram rodadas para verificar em que medida os resultados do teste de percepção correlacionavam-se com os do teste de 
produção. Como mostra a TAB. 3, todas as correlações obtidas foram fracas e não significativas, o que sugere que uma boa percepção dos sons-alvo não implica melhor produção e vice-versa. De fato, quando olhamos as médias dos testes de percepção e produção, constatamos situações diferentes para as duas sibilantes: /z/ é consideravelmente mais bem percebido do que produzido, ao contrário de /s/, que é produzido corretamente com uma frequência um pouco maior do que é percebido.

\section{TABELA 3}

Correlações entre a percepção e a produção de /s/ e /z/

\begin{tabular}{l|l|l|l|l}
\hline \multicolumn{2}{l}{} & /z/ percepção & /s/ produção & /z/ produção \\
\hline /s/ percepção & Coeficiente correlacional (valor de p) & $.307(.265)$ & $.022(.937)$ & \\
/z/ percepção & Coeficiente correlacional (valor de p) & & $.145(.607)$ & $.320(.244)$ \\
/s/ produção & Coeficiente correlacional (valor de p) & & & $-.439(.102)$ \\
\hline
\end{tabular}

$\mathrm{p}=$ probabilidade

A falta de resultados significativos nas correlaçóes pode estar relacionada ao número limitado de participantes do presente estudo, mas também pode ser uma consequência da influência de outras variáveis, tais como o nível de proficiência dos participantes, a grafia das palavras testadas e o contexto fonológico em que os sonsalvo apareciam. Para verificar essas possibilidades, passaremos a discutir os resultados que nos permitem responder à pergunta de pesquisa 3:

3) Qual o tipo de correlação entre a percepção e a produção de /s/ e /z/ e o nível de proficiência dos participantes?

Correlações de Spearman foram rodadas para verificar em que medida os resultados dos testes de percepção e produção correlacionavam-se com a variável nível de proficiência. Como mostra a TAB. 4, constatou-se que todas as correlações são fracas e não significativas, indicando que o nível de proficiência dos alunos não está correlacionado com a forma com que eles percebem e produzem as sibilantes. Cabe notar que todos os coeficientes de Spearman indicam baixas correlações negativas, sugerindo que quanto maior o nível de proficiência, pior o desempenho nos testes. Examinando os dados, percebe-se, realmente, que há alunos do nível 1 (ex.: participante 12) que conseguiram cerca de $90 \%$ de acertos no teste de produção de /z/, enquanto alunos do nível 6 (ex.: 
participante 1) obtiveram índices muito baixos de acerto no mesmo teste (no caso do participante 1 , o índice foi de $0 \%$ ). Embora seja esperado que à medida que a proficiência na L2 avance, o desempenho seja melhor, esse nem sempre é o caso na aquisição da pronúncia em L2, que tende a fossilizar quando os aprendizes não tomam consciência das diferenças entre os inventários fonéticos e fonológicos da L1 e da L2 já nos estágios iniciais de aprendizagem (TOWELL; HAWKINS, 1994; BAPTISTA, 1995).

TABELA 4

Correlações entre o nível de proficiência e a percepção e a produção das fricativas alveolares

\begin{tabular}{c|l|c}
\hline \multicolumn{2}{l|}{} & Nível de proficiência \\
\hline /s/ percepção & Coeficiente correlacional (valor de $\mathrm{p})$ & $-.257(.356)$ \\
/z/ percepção & Coeficiente correlacional (valor de $\mathrm{p})$ & $-.006(.982)$ \\
$/ \mathrm{s} /$ produção & Coeficiente correlacional (valor de $\mathrm{p})$ & $-.154(.584)$ \\
/z/ produção & Coeficiente correlacional (valor de $\mathrm{p})$ & $-.281(.310)$ \\
\hline $\mathrm{p}=$ probabilidade
\end{tabular}

Cabe lembrar, porém, que os dados foram coletados com apenas 15 participantes e que $75 \%$ desses participantes estavam matriculados no nível 1 , não havendo, assim, um número representativo de participantes nos demais níveis de proficiência. Certamente essa falta de amplitude nos dados é uma limitação para a análise da relação entre o nível da proficiência e a percepção e a produção dos sons-alvo. Passemos agora aos resultados para a discussão dos efeitos da ortografia e do contexto fonológico:

4) Em que medida a percepção e a produção dos sons /s/ e /z/ são influenciadas pela ortografia e pelo contexto fonológico?

As mesmas palavras (20 pares mínimos) foram utilizadas tanto no teste de percepção quanto no de produção. Para verificar o efeito da ortografia, calculamos o total de acertos para cada tipo de grafia dos sons-alvo, conforme aparecia nos testes. A TAB. 5 apresenta números totais e porcentagens de acertos para cada grafia, separadas para cada teste. Podemos observar que as porcentagens de acerto para todas as grafias sempre são maiores para o teste de percepção, sendo a grafia mais fácil <ss $>$ e a mais difícil <ç>. Já no teste de produção, a grafia mais fácil é também $<s s>$, e as mais difíceis $<\mathrm{z}>\mathrm{e}<\mathrm{s}>$. 
É interessante notar que as duas grafias do $\mathrm{PB}$ que não existem em espanhol $(<s s>\mathrm{e}<c ̧>)$ geram resultados bastante diferentes. A grafia <ss> éa mais fácil tanto para o teste de percepção quanto para o de produção, enquanto a grafia $<$ ç>, que geralmente resulta em palavras grafadas com $<\mathrm{z}>\mathrm{em}$ espanhol, é a mais fácil para o teste de percepção e a terceira mais difícil para o teste de produção.

\section{TABELA 5}

Total geral e porcentagem de acertos para cada tipo de grafia

\begin{tabular}{l|c|r|r}
\hline Grafia & Número de palavras testadas & \multicolumn{1}{|c}{ Percepção } & \multicolumn{1}{|c}{ Produção } \\
\hline$<$ ss> & 3 & $41(91,11 \%)$ & $37(82,22 \%)$ \\
$<\mathrm{c}>$ & 6 & $79(87,78 \%)$ & $63(70 \%)$ \\
$<\mathrm{z}>$ & 8 & $98(81,67 \%)$ & $51(42,50 \%)$ \\
$<\mathrm{s}>$ & 16 & $185(77,08 \%)$ & $123(51,25 \%)$ \\
$<\mathrm{ç}>$ & 6 & $67(74,44 \%)$ & $62(68,89 \%)$ \\
\hline
\end{tabular}

Número máximo de acertos $=$ número de palavras ${ }^{*}$ número de participantes $(15)$

Infelizmente não é possível comparar nossos resultados com os apresentados por Akerberg (2001) para a percepção de /s/ e /z/, e por Sobral, Nobre e Freitas (2006) para a produção dos mesmos sons. Nenhum desses trabalhos traz a tabulação dos dados por tipo de grafia, eles tecem apenas comentários gerais sobre os possíveis efeitos da ortografia na pronúncia dos sons-alvo. Passemos agora aos resultados que examinam a influência do contexto fonológico.

Cabe lembrar que os sons-alvo foram testados apenas na posição de ataque silábico, sendo que as palavras utilizadas apresentavam o som em dois tipos de contexto fonológico: entre dois sons vocálicos ( $\mathrm{V}_{-} \mathrm{V}$, 'casa') ou em início de palavra e seguido por uma vogal (\#_V, 'zelo'). A TAB. 6 mostra os resultados para cada tipo de contexto. Podemos observar que a porcentagem de acertos é sempre menor para o contexto intervocálico $\left(V_{-} V\right)$, em especial para o teste de produção. Ou seja, quando os sons / s/ e /z/ aparecem em início de palavra, e também em sílaba tônica, como era o caso das palavras utilizadas nos testes, os participantes apresentaram um desempenho melhor tanto no teste de percepção quanto de produção. Provavelmente esse fato se deve a uma maior saliência do som-alvo quando isso aparece em início de palavra e em sílaba tônica. Futuras pesquisas precisam investigar essa possibilidade, pois esse tipo de informação pode contribuir para o ensino da pronúncia de $/ \mathrm{s} / \mathrm{e} / \mathrm{z} /$. 
TABELA 6

Total de acertos por tipo de contexto fonológico

\begin{tabular}{l|r|r|r|r}
\hline & V_V percepção & \#_V percepção & V-V produção & \#_V produção \\
\hline $\begin{array}{l}\text { Número de } \\
\text { palavras testadas }\end{array}$ & 405 & 195 & 405 & 180 \\
Total de acertos & $323(79,75 \%)$ & $161(82,56 \%)$ & $219(54,07 \%)$ & $117(65 \%)$ \\
\hline
\end{tabular}

\section{Considerações Finais}

Nosso estudo comparando e correlacionando a percepção e a produção das duas fricativas alveolares do $\mathrm{PB}$ por hispano-falantes mostra que as duas consoantes têm bom índice de percepção (acima de 70\%), mas que o desempenho dos participantes na percepção de /z/ é um pouco melhor. Esse resultado sugere que o som que não existe na L1 dos participantes é mais fácil de ser percebido, o que de certa forma contraria nossas expectativas. Tal resultado também foi encontrado no estudo de Akerberg (2001), nos dados do teste 1 aplicado pela autora. Futuras pesquisas precisam investigar melhor possíveis explicações para esses resultados, levando em consideração o efeito da ortografia, do grau de familiaridade dos participantes com as palavras incluídas nos testes e do status das palavras na L1 dos participantes (cognatas / não cognatas).

Os resultados do teste de produção indicam que /s/ é produzido com bom índice de correção (cerca de 84\%), mas /z/ impõe bastante dificuldade, gerando um índice de acertos na casa dos 35\%. Tal resultado era esperado e corrobora o estudo de Sobral, Nobre e Freitas (2006), que também constataram que o som inexistente na $\mathrm{L} 1$ dos participantes hispano-falantes $(/ \mathrm{z} /)$ suscitava mais dificuldade de produção, geralmente causada pela grafia das palavras e pela transferência de processos fonológicos da L1 na pronúncia da L2. De fato, as palavras grafadas com $<$ s $>$ em contexto intervocálico e $<\mathrm{Z}>$ em posição de início de sílaba seguido de vogal geraram muitas dificuldades no teste de produção, revelando que os alunos talvez desconheçam as regras de pronúncia para essas grafias em determinados contextos fonológicos, ou que talvez tenham dificuldades em suprimir o processo de transferência das regras fonológicas do espanhol.

Um dos objetivos do presente estudo era verificar a relação entre percepção e produção das fricativas alveolares. Nossos resultados, que mostraram correlaçōes fracas e não significativas entre as duas habilidades, não nos permitem fazer afirmaçóes contundentes. Provavelmente devido ao número limitado de participantes 
que forneceram dados para o estudo, não é possível sugerir se a percepção auditiva dos dois sons facilita a sua produção. O que nossos resultados mostram é que /z/ é mais bem percebido que $/ \mathrm{s} /$, mas sua produção é mais difícil. Embora esses resultados não sejam significativos, há uma indicação de que a percepção auditiva em si não explica a forma como os sons-alvo são produzidos, e que temos de levar em consideração outras variáveis que influenciam na percepção e na produção dos sons da L2.

Em nosso estudo, examinamos três possíveis variáveis que podem, de certa forma, intermediar a relação entre a percepção e a produção dos sons da L2: nível de proficiência, ortografia e contexto fonológico. Primeiramente, correlacionamos os resultados dos testes de percepção e de produção com o nível de proficiência dos participantes, o que gerou correlações fracas e não significativas, mostrando que a proficiência não levou os participantes a ter um melhor desempenho. Sugerimos que a inexistência de correlações significativas nesse caso indicam que a pronúncia dos sons /s/ e /z/ tendem a ser alvo de fossilização e precisam ser intensivamente trabalhadas ainda nos estágios iniciais de aprendizagem de PB como L2. No que concerne à variável ortografia, vimos que palavras grafadas com $<$ s $>,<\mathrm{z}>\mathrm{e}<\mathrm{ç}>$ causam bastantes dificuldades na produção, sendo importante enfatizar as diferentes correspondências grafo-fono-fonológicas entre a L1 e a L2, bem como discutir as diferenças ortográficas das palavras em PB e espanhol. Finalmente, o contexto fonológico também parece ter um papel importante no que diz respeito à produção dos sons-alvo, sendo que palavras nas quais esses sons apareciam em contexto intervocálico, geralmente em sílaba átona, mostraramse mais difíceis de ser produzidas.

Pensando nas implicações pedagógicas dos resultados obtidos, seria importante que os cursos de PB incluíssem instrução explícita sobre as possíveis pronúncias das grafias $\langle\mathrm{s}\rangle \mathrm{e}<\mathrm{z}\rangle$, em especial quando essas grafias ocorrem em contexto intervocálico (ex.: 'casa', 'aza') ou em posição de ataque silábico seguido de vogal (ex.: 'zero', 'zinco'). É importante que o alunos hispano-falantes saibam que, em $\mathrm{PB}$, a grafia $<\mathrm{s}>$ em contexto intervocálico e que a grafia $<\mathrm{z}>$ em posição de ataque silábico implicam a produção da cosoante vozeada [z].

Futuras pesquisas, com um volume maior de participantes e com um controle maior das variáveis nível de proficiência, grau de familiaridade das palavras e status da palavra na L1 (cognata / não cognata) são ainda necessárias para melhor elucidar a complexidade entre a percepção e a produção dos sons /s/ e /z/ por hispano-falantes. No entanto, o presente estudo já aponta alguns 
caminhos interessantes tanto para as pesquisas quanto para o ensino da pronúncia dos sons-alvo.

\section{Notas}

${ }^{1}$ A palavra 'cinco' foi removida da análise porque foi omitida no teste de produção, por erro de digitação.

${ }^{2}$ Ressalta-se que as demais grafias, <ç>, <ss >, não ocorrem em início de palavra em PB.

\section{Referências}

AKERBERG, M. A importância da palavra escrita para a pronúncia. In: SIMŌES, A. R. M.; CARVALHO, A. M.; WEIDEMANN, L. (Org.). Português para falantes de espanhol: Artigos selecionados escritos em português e inglês. Campinas: Editora Pontes, 2004, p. 115-124.

AKERBERG, M. A interpretação dos fonemas $/ \mathrm{s} / \mathrm{e} / \mathrm{z} / \mathrm{em}$ português por alunos falantes de espanhol. Anais do IV Congresso da SIPLE, Rio de Janeiro: PUC-Rio, 2001, CD.

BAPTISTA, B. O. Aspectos da teoria cognitiva: Aplicações à aquisição / aprendizagem e ao ensino da pronúncia de línguas estrangeiras. CONGRESSO BRASILEIRO DE LINGÜÍSTICA APLICADA, IV. Anais... Campinas, SP: Unicamp, 1995. p. 495-502.

BASSETTI, B. Orthographic input and second language phonology. In: PISKE, T.; YOUNG-SCHOLTEN, M. (Org). Input Matters in SLA. Bristol: Multilingual Matters, 2009, p. 191-206.

CONDE, X. F. Introducción a la Fonética y Fonología del Español. Ianua Revista Philologica Romanica, supl. 4, 2001, p. 1-23.

CRISTÓFARO-SILVA, T. Fonética e Fonologia do português: roteiro de estudos e guia de exercícios. São Paulo: Contexto, 2002.

FLEGE, J. E. Effects of equivalence classification on the production of foreign language speech sounds. In: JAMES, A.; LEATHER, J. (Ed.). Sound Patterns of Second Language Acquisition. Dortrecht: Foris, 1987. p. 9-39.

FLEGE, J. E. Second language speech learning: Theory, findings, and problems. In: STRANGE, W. (Ed.), Speech Perception and Linguistic Experience: Issues in CrossLanguage Research. Timonium, MD: York Press, 1995. p. 233-277. 
FLEGE, J. E.; MACKAY, A. I. R. A.; MEADOR, D. Native Italian speakers perception and production of English vowels. Journal of the Acoustical Society of America, v. 106, n. 5, p. 1-15, 1999.

HAZAN, V.; SENNEMA, A.; FAULKNER, A., ORTEGA-LLEBARIAD, M., IBA, M.; CHUNG, $\mathrm{H}$. The use of visual cues in the perception of non-native consonant contrasts. Journal of the Acoustical Society of America, v. 119, n. 3, 2006, p. 1740-1751.

HUALDE, J. I. The Sounds of Spanish. New York: Cambridge University Press, 2005.

KLUGE, D. C. Brazilian EFL learners identification of word-final m-n: Nativel nonnative realizations and effect of visual cues. Saarbrücken: Lambert Academic Publishing, 2010.

ROCHET, B. L. Perception and productions of second-language speech sounds by adults. STRANGE, W. (Org.). Speech Perception and Linguistic Experience: Issues in Cross-Language Research. Timonium, MD: York, 1995. p. 379-411.

SILVEIRA, R. The role of task-type and orthography in the production of wordfinal consonants. Revista de Estudos da Linguagem, v. 15, n. 1, p. 143-176, 2007.

SOBRAL, C. da S.; NOBRE, M. M. R.; FREITAS, M. A. Relação fone-fonemagrafema na produção oral de aprendizes de PLE. Portuguese Language Journal, v. 1, p. 1-18, 2006.

TOWELL, R.; HAWKINS, R. Approaches to second language acquisition. Bristol: Multilingual Matters Ltd. 1994.

YOUNG-SCHOLTEN, M. Orthographic input in L2 phonological development. In: BURMEISTER, P.; PISKE, T; RHODE, A. (Ed.). An Integrated View of Language Development: Papers in Honour of Henning Wode. Trier: Wissenschaftlicher Verlag Trier, 2002. p. 263-279.

YOUNG-SCHOLTEN, M.; ARCHIBALD, J. Second Language Syllable Structure. In: ARCHIBALD, J. (Ed.) Second Language Acquisition and Linguistic Theory. Oxford: Blackwell, 2000. p. 64-97.

ZIMMER, M. C. A.; SILVEIRA, R.; ALVES, U. K. Pronunciation Instruction for Brazilians: Bringing Theory and Practice Together. Newcastle upon Tyne: Cambridge Scholars Publishing, 2009. 